\title{
REINLE, Christine, Ulrich Riederer (ca. 1406-1462): Gelehrter Rat im Dienste Kaiser Friedrichs III.
}

Joseph Morsel

\section{OpenEdition}

\section{Journals}

Édition électronique

URL : http://journals.openedition.org/ifha/1902

DOI : 10.4000/ifha.1902

ISSN : 2198-8943

Éditeur

IFRA - Institut franco-allemand (sciences historiques et sociales)

Référence électronique

Joseph Morsel, «REINLE, Christine, Ulrich Riederer (ca. 1406-7462): Gelehrter Rat im Dienste Kaiser Friedrichs III. », Revue de I'IFHA [En ligne], Date de recension, mis en ligne le 01 janvier 1995, consulté le 22 septembre 2020. URL : http://journals.openedition.org/ifha/1902 ; DOI : https://doi.org/10.4000/ ifha. 1902

Ce document a été généré automatiquement le 22 septembre 2020.

(C)IFHA 


\title{
REINLE, Christine, Ulrich Riederer (ca. 1406-1462): Gelehrter Rat im Dienste Kaiser Friedrichs III.
}

\author{
Joseph Morsel
}

1 Le titre de l'ouvrage de K.-F.K. est une bonne expression de la manière dont les Habsbourg sont considérés en Allemagne et en Autriche: si « Les Habsbourg au Moyen Age » reçoivent comme sous-titre " De Rodolphe Ier à Frédéric III », c'est dire que le Moyen Age des Habsbourg commence avec leur premier accès au trône royal dans l'Empire: auparavant, ils ne retiennent pas l'attention (ils ne sont d'une certaine manière que des "pré-Habsbourg »). C'est dire aussi l'existence d'une nette tendance téléologique: il s'agit d'étudier les racines médiévales de l'empire habsbourgeois de l'époque moderne (l'arrêt avant Maximilien est symptomatique). L'étude de K.-F.K., utile et bien documentée, est menée de manière chronologique suivant une perspective dynamique qui articule une première affirmation habsbourgeoise (Rodolphe Ier, Albert Ier), brisée par des oppositions trop fortes (Wittelsbach, Luxembourg, contraignant Frédéric le Beau à l'anti-royauté puis ses successeurs à l'absence de l'Empire) et des contradictions internes (querelles patrimoniales comme sous-produit de l'effort territorial vers lequel doit se réorienter la dynastie), blocages dépassés par Albert II et surtout Frédéric III, considéré comme le véritable fondateur de la puissance impériale des Habsbourg, parachevant ainsi l'oeuvre entreprise par Rodolphe Ier.

C'est sans doute cette opinion partagée qui explique que ces deux extrémités de la chaîne médiévale des Habsbourg royaux aient précisément chacune fait l'objet d'un colloque (la prétendue occasion du 700e ou du 500e anniversaire de leur mort ne devant pas faire illusion). Le règne de Rodolphe Ier, conçu comme le liquidateur de l'héritage des Staufen et l'initiateur de nouvelles forces dans l'Empire, s'est ainsi vu consacrer dix contributions, qui le mettent en perspective dans l'histoire de la monarchie impériale (par rapport aux Staufen, dans la série des " petits rois ", par rapport à la monarchie française), évoquent le tournant dynastique et territorial du pouvoir royal et princier dans l'Empire, rappellent la pertinence des notions de proximité ou de distance royale 
(Königsnähe/Königsferne) dans un Empire vaste et hétérogène (Germanie, Italie, Bohême, Cantons Suisses, etc.).

3 L'ouvrage sur Frédéric III comprend deux fois plus de contributions (signe de l'importance reconnue à l'Empereur?), réparties en deux sections: d'une part des études montrant les interventions de Frédéric III à divers niveaux de la société et du paysage politique de l'Empire (villes de Linz, Feldkirch, Memmingen, Wetzlar, Aix-laChapelle, Nuremberg; abbaye de Saint-Gall, comtes de Wurtemberg, comtes de Solms, landgraves de Thuringe, nobles et rois de Bohême); d'autre part des études portant sur des aspects du "système politique » de Frédéric III en tant qu'Empereur/prince territorial (préoccupations et pratique judiciaires, personnel politique et administratif, rôle de l'impératrice Eléonore, postérité charnelle - Maximilien - et spirituelle à l'époque moderne). Un index clôt heureusement ce florilège quelque peu décousu.

Les deux ouvrages de W.B. (qui a aussi participé à l'ouvrage précédent et auquel on doit également un ouvrage sur Sigismond recensé dans ce même Bulletin) constituent en revanche deux contributions importantes à l'histoire médiévale des Habsbourg, toutes deux articulées autour du problème du rapport entre politique impériale et politique dynastique/territoriale. Les efforts récurrents des Habsbourg pour se maintenir et s'étendre en Souabe (l'« Autriche antérieure ») entre 1386 (défaite de Sempach devant les Suisses) et 1486 (le rachat de l'avouerie impériale sur la Souabe) permettent à W.B., en une étude très fouillée et riche de nouveaux points de vue, de montrer les difficiles rapports entre royauté et principauté (que le roi soit un Luxembourg comme Sigismond ou un Habsbourg comme Frédéric III) dans une région (et la seule) où le fisc impérial avait encore de l'importance et où l'Empire constituait toujours (même pour les Cantons Suisses) la seule véritable source de légitimité. Le second ouvrage de W.B. inverse la perspective: il ne s'agit plus de montrer les problèmes posés par la royauté impériale et aussi la ligue des Suisses à la constitution d'une principauté territoriale (celle des Habsbourg en " Autriche antérieure ») que de rectifier l'image d'un « temps des principautés » ayant remplacé le « temps de la royauté » morte avec les Staufen (on rapprochera sur ce point cet ouvrage de W.B. avec les communications au colloque sur Rodolphe concernant la royauté). L'examen des rapports entre les rois des Romains et les Habsbourg de 1273 (élection de Rodolphe Ier et fin de l'Interrègne) à 1437 (mort de Sigismond, clôturant la période d'exclusion impériale des Habsbourg) fait apparaître une royauté bien moins dépassée qu'on ne l'a dit, capable encore de briser une principauté territoriale (1415). L'élaboration précoce d'un discours dynastique (celui de la « Maison d'Autriche », domus Austriae, Haus Österreich) - dont l'ouvrage présente en annexe les principales sources - s'avère particulièrement efficace pour mener à bien l'expansion territoriale tous azimuts des diverses lignées. Prenant aussi le contre-pied de la mythologie hélvétique - comme l'avait fait avant lui Karl Mommsen dès 1958, mais dont les recherches n'avaient pas été prises en considération -, W.B. réduit les Cantons Suisses à un cas particulièrement réussi du phénomène des ligues caractérisant tout le Sud de l'Empire, succès déterminé avant tout par la confrontation royauté/principauté évoquée. Les Habsbourg, les Suisses et les Rois des Romains ne sont plus ce qu'ils étaient - ou du moins ce qu'on croyait qu'ils étaient (une fois Mommsen et certains aspects de la recherche récente sur le XIIIe s. mis de côté, comme le fait W.B...).

5 La complexité des relations entre les confédérés suisses et les Habsbourg - au lieu de la mythologie stylisant l'opposition entre l'Autrichien agresseur et le Suisse libertaire et résistant, telle qu'elle a été fixée au XVIIIe s. par Aegidius Tschudi - apparaît 
particulièrement bien dans l'étude de la Guerre de Zurich d'A.N. Celle-ci a éclaté entre Schwyz et Zurich au sujet de l'héritage du comte de Toggenburg; les Habsbourg (en l'occurence Frédéric, élu peu après Roi des Romains), soucieux de récupérer les biens perdus dans la région à la suite du bannissement de 1415, s'en sont mêlés si bien que Zurich a fini par s'allier aux Habsbourg contre les autres villes suisses dans une guerre (1443-1446) qui a tenu tout le Sud-Ouest de l'Empire en haleine et qui a surtout joué un rôle déterminant dans le processus de prise de distance des Suisses (vainqueurs de Zurich et de son allié autrichien) vis-à-vis de l'Empire. Les événements sont retracés dans le détail, les relations austro-suisses étant elles-mêmes reprises en considération depuis la fin du XIVe s. Un dossier conséquent ( 85 p.) de sources publiées en annexe clôt l'ouvrage.

6 C'est dans le contexte de ces années difficiles qu'Ulrich Riederer est entré au service de Frédéric III en tant que conseiller, et on le voit jouer un rôle notable lors des pourparlers de paix et des difficiles négociations y afférentes à partir de 1446 . Ce personnage, reconnu quelques années plus tard (1459) par l'échevin nurembergeois Hans Pirckheimer comme l'un des trois hommes-clés de l'Empire, condisciple du futur pape Pie II qui l'a honoré dans ses mémoires et dont l'importance dans les affaires de l'Empire lui attira des inimitiés proportionnelles et lui valut d'être assassiné en 1462, peu après la paix de Wiener Neustadt, vient de se voir consacrer une volumineuse et dense biographie. Originaire d'une famille d'officiers ducaux de Bavière et d'abord au service du duc après ses études universitaires, il est ensuite passé au service de Frédéric III et a été mêlé à tous les projets politiques et diplomatiques importants de l'Empereur. En suivant Riederer, l'étude de C.R. donne ainsi un intéressant éclairage « de l'intérieur » du fonctionnement de la cour impériale, notamment des groupes de pression agissant sur les prises de décision.

7 Joseph MORSEL 